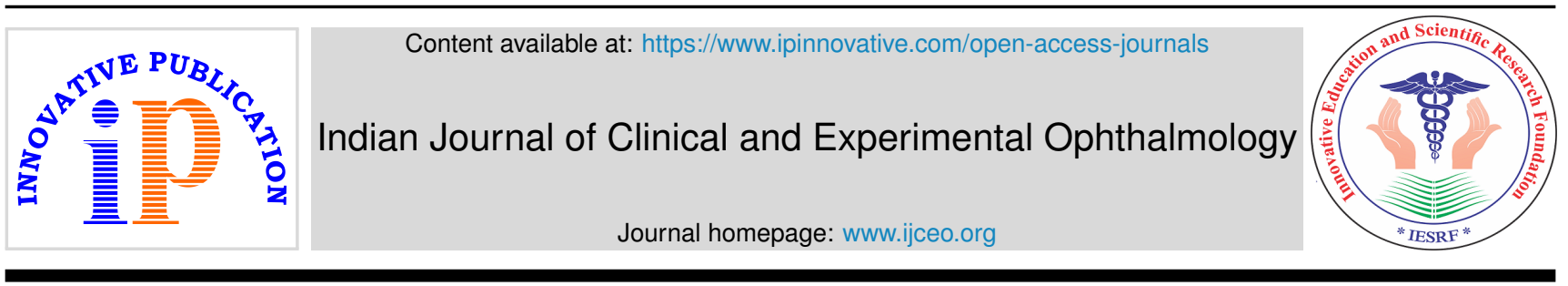

Original Research Article

\title{
Study of dry eye in diabetes mellitus type II and it's association with diabetic retinopathy
}

\author{
O Revana Reddy ${ }^{1} *$, B Asritha ${ }^{1}$, K Sushma $^{1}$ \\ ${ }^{1}$ Dept. of Ophthalmology, Narayana Medical College and Hospital, Nellore, Andhra Pradesh, India
}

\section{A R T I C L E I N F O}

\section{Article history:}

Received 21-03-2020

Accepted 02-07-2020

Available online 22-12-2020

\section{Keywords:}

Dry eye disease

Diabetic retinopathy

Schirmer's test

Tear break up time test

\begin{abstract}
A B S T R A C T
Background: Dry eye disease and diabetic retinopathy are complications in diabetes mellitus. However association between diabetes mellitus type II and dry eye disease are still unclear. Objectives of this study objective is was to analyse association between dry eye disease and diabetic retinopathy in patients with type 2 diabetes mellitus.

Materials and Methods: A prospective study on seventy patients of diabetis mellitus type II/patients undergone indirect ophthalmoscopy and retinal photography, and the dry eye syndrome analysis using tear break up time and Schirmer tests. Diabetic retinopathy was graded.

Results: In this study, there was no association identified among the age, sex \& duration of diabetes mellitus type II disease and diabetic retinopathy. $52.8 \%(\mathrm{n}=37)$ patients were observed to be suffering from dry eye syndrome and it was common in older and female patients. Diabetic retniopathy observed in $67.1 \%(\mathrm{n}=47)$ patients. Upon classification, $34.2 \%(\mathrm{n}=24)$ belongs to non-proliferative diabetic retinopathy, $27.1 \%(n=19)$ belong to severe NPDR and $5.7 \%(n=4)$ belongs to proliferative DR. TBUP was observed as $\leq 10$ seconds. Moderate NPDR was significantly high in diabetes mellitus type II patients with dry eye disease. Statistically significant association observed between diabetic retinopathy and dry eye disease.

Conclusion: The dry eye disease prevalence observed as $52.8 \%$ patients. Statistically significant association observed between severity of dry eye disease with duration of diabetes mellitus disease and the degree of diabetic retinopathy. There was significant association identified between diabetic retinopathy and dry eye disease.

(c) This is an open access article distributed under the terms of the Creative Commons Attribution License (https://creativecommons.org/licenses/by/4.0/) which permits unrestricted use, distribution, and reproduction in any medium, provided the original author and source are credited.
\end{abstract}

\section{Introduction}

Diabetes mellitus (DM) was major public health problem and prevalence will be reach 380 millions by 2025 . $^{1,2}$

Diabetic retinopathy, leading cause of visual impairment in working age people of the world. This disease starts with a progressive reduction in perfusion of the capillary bed in retina. Neovascularization will be develop to compensate for retinal ischemia. ${ }^{3}$

Dry eye, defined as evaporative and lacrimal aqueous layer deficiency, excessive evaporation due to deficiency of the lipid layer. ${ }^{4,5}$ Type 2 diabetes mellitus is a major risk factor for dry eye disease and diabetic retinopathy. Aging

\footnotetext{
* Corresponding author.

E-mail address: orevanareddy @gmail.com (O. R. Reddy).
}

process and post menopause are another risk factors for dry eye disease. ${ }^{6,7}$ Various studies shows that higher incidence of dry eye was observed among diabetes mellitus. ${ }^{8}$ But, the information about dry eye disease in proliferative diabetic retinopathy is not sufficient.

Hence, current study aimed to identify the prevalence of dry eye disease and their association with diabetic retinopathy.

\section{Materials and Methods}

A prospective study conducted on seventy diabetic patients at department of Ophthalmology of Narayana Medical College and hospital, Nellore, Andhra Pradesh for 2 years duration. 
Inclusion criteria of this study was/diabetes mellitus type II, based on glucose level (normal limit $<110 \mathrm{mg} / \mathrm{dl}$ ) and exclusion criteria was diabetes mellitus type I; contact lens wear, cigarette smoking, lasic surgery, rheumatoid arthritis, Sjogren's syndrome, Parkinson, users of oral contraceptives and tricyclic antidepressants, drugs to treat high blood pressure, vitamin A deficiency and pregnancy.

Clinical exams like duration the disease diabetes and history was collected from medical records.

\subsection{Evaluation of dry eye disease}

Patients having complaints of dry eye disease e.g. ocular discomfort, gritty sensation, redness and excessive tearing established by Tear break-up time, and schirmer's test. Dry eye disease was graded in to mild, moderate and severe. Patients were further evaluated for blepharitis and mebomian gland dysfunctions by using slit lamp examinations.

\subsection{Diabetic retinopathy examination}

Fundus examination performed to check retinal changes. The grading of diabetic retinopathy was done by slit lamp biomicroscopy and fundus photography was done by fundus camera. Fasting and post-prandial blood sugar, $\mathrm{HbA} 1 \mathrm{C}$ assays were performed in all patients. Patients were classified into NPDR, PDR and NDPR.

\subsection{Statistics}

Data represented as mean and significance between discrete variables performed using chi-square test. Statistical significance was set to $\mathrm{p}<0.05$ and data analysis carried out by SPSS software.

\section{Results}

The mean age was $51.5 \pm 10.6$ years $(35$ years in men and 45 years in women). Totally $52.8 \%(\mathrm{n}=37)$ patients were suffering from dry eye disease, $(\mathrm{p}=0.45)$. The dry eye disease incidence was high in 60-75 year age without any statistical significance.

In dry eye disease patients, the mean disease duration of diabetes mellitus type II was $10.5 \pm 6.8$ years, but, this was $9.0 \pm 6.5$ years in patients without dry eye disease with significant correlation $(\mathrm{p}=0.01)$.

Hence the dry eye disease was significantly higher in patients with dry eye disease.

In dry eye disease patients, $40 \%$ suffered from gritty sensation and $25 \%$ had soreness. The tear break up time (TBUP) was found to be $\leq 10$ seconds in dry eye disease subjects.

Diabetic retinopathy was found in $47(67.14 \%)$ patients, and $24(34.28 \%)$ patients were non proliferative diabetic retinopathy (NPDR) and 19 patients $(27.14 \%)$ were severe
NPDR and $4(5.714 \%)$ patients were proliferative DR (PDR). Moderate non-proliferative diabetic retinopathy (NPDR) (33\%) was significantly high in diabetes mellitus patients with dry eye disease. In this study, no patients observed with very severe NPDR. Statistically significant correlation $(\mathrm{p} \leq 0.001)$ observed between diabetic retinopathy and dry eye disease.

\section{Discussion}

Type 2 diabetes mellitus, the risk factor for dry eye disease known to cause of diabetic retinopathy.

Dry eye disease can affect the quality of life by inducing ocular discomfort, visual disturbance, and blindness due to diabetes mellitus type II in age group of 20-74 years. It also been observed that age and gender seems to affect the dry eye disease.

In our study, dry eye disease incidence was high due to longer diabetic disease duration and also observed high in females. Study by Moss SE, et al, identified the incidence of dry eye disease as $14.4 \%$.

In current study, the prevalence of diabetic retinopathy was increased according to increase in the age. The age adjusted prevalence in men and women was $16.7 \%$ and $11.4 \%$ respectively. ${ }^{9}$ This increase may be due to hormonal status and pre- \& post-menopausal period.

In this study, the prevalence of dry eye disease observed as very high. Main risk factors like aging, dry weather in this area/weather and neurological disorder in diabetes mellitus type 2 .

Whereas, previous other reports shows the incidence of diabetic retinopathy in late-onset diabetes mellitus was low in comparison to young-onset diabetes mellitus. ${ }^{10,11}$

A previous report on 150 patients shows that 21(14\%) patient had some form of diabetic retinopathy and $10(6.6 \%)$ of these patients had threaten diabetic retinopathy. Patients with diabetic retinopathy showing significantly higher association than median duration of diabetes mellitus type II with 5 years duration compared with patients without diabetic retinopathy ( 3.5 years duration). ${ }^{12}$

Our study reveals significant correlation between sex and grades of diabetic retinopathy.

Lower grade of diabetic retinopathy highly common in women and higher grades of diabetic retinopathy was observed highly commonly in men. This type of association also observed in Rema et al., study. ${ }^{13}$ Many other studies demonstrates the significant correlation between dry eye disease and stages of diabetic retinopathy.

Hence, this study demonstrates the association between dry eye disease and diabetic retinopathy in diabetes mellitus type II patients.

Current study results showed the significant association between prevalence of diabetic retinopathy and diabetes duration. This type of association disease pattern was also reported in Klein et al. ${ }^{14}$ 
Glycemic control, may be one of the preventing factor in developing dry eye disease. In our study, results shows glycemic status was not under control in females with dry eye disease. This implies that gender plays an important role in identifying the close association between poor glycemic control and prevalence of dry eye disease. Studies by Shaik $^{15}$ and Najafi et al., ${ }^{16}$ demonstrates the significant correlation between the $\mathrm{HbA} 1 \mathrm{c}$ and the presence of dry eye disease.

Normal microbial flora was present on conjunctiva, which contributes to defence the ocular surface.

Diabetes mellitus type II may be inclined for the increased risk for opportunistic colonization of the eyelids, results to blepharitic presentations, finally leads to compromised tear film lipid layer with increased evaporation and decreased tear secretion.

\section{Conclusion}

Examination for dry eye disease should be an integral part of the assessment of diabetic eye disease. Study shows that glycemic status of the patient definitely shows the impact on the incidence of dry eye disease in subjects with diabetes mellitus type II. Study also demonstrates that both dry eye and diabetic retinopathy had significant correlation with HbA1c. In conclusion, current study suggests the surveillance of patients with diabetes mellitus type II and good glycemic control are the important key factors for preventing the dry eye disease and also diabetic retinopathy.

\section{Source of Funding}

None.

\section{Conflict of Interest}

The authors declare that there is no conflict of interest.

\section{References}

1. Verma R, Khanna P. National programme on prevention and control of diabetes in India: Need to focus. Aust Med J. 2012;5:310-5.

2. Maurya RP. Diabetic retinopathy :My brief synopsis. Indian J Clin Exp Ophthalmol. 2015;1(4):189-90.

3. Latkany R, Miller D, Zeev MSB. Diagnosis of dry eye disease and emerging technologies. Clini Ophthalmol. 2014;8:581. do1:10.2147/opth.s45444.

4. Foulks GN, Forstot SL, Donshik PC, Forstot JZ, Goldstein MH, Lemp MA, et al. Clinical Guidelines for Management of Dry Eye Associated with Sjögren Disease. Ocul Surf. 2015;13(2):118-32. do1:10.1016/1.jtos.2014.12.001

5. Maurya RP. Dry eye disease: An overview. Indian J Clin Exp Ophthalmol. 2018;4(4):433-4. 101:10.1823/2395-145 1.2018.0096

6. Yokoi N, Mossa F, Tiffany JM, Bron AJ. Assessment of Meibomian Gland Function in Dry Eye Using Meibometry. Arch Ophthalmol. 1999;117:723-9.

7. Maurya RP, Singh VP, Chaudhary S, Roy M, Srivastav T. Prevalence of severe dry eye disease in postmenopausal women in North India: A teaching hospital study. Indian J Obstet Gynecol Res. 2019;6(1):94-6. do1:10.1823/2394-2754.201000211

8. Klaassen-Broekema N, Mackor AJ, Bijsterveld OPV. The diagnostic power of the tests for tear gland related keratoconjunctivitis sicca. Neth J Med. 1992;40(3-4):113-9.

9. Moss SE, Klein R, Klein B. Prevalence of and Risk Factors for Dry Eye Syndrome. Arch Ophthalmol. 2000;118:1264-8.

10. Nathan DM, Singer DE, Godine JE, Harrington HC, Permulter LC. Retinopathy in older type II diabetics: association with glucose control. Diabetes. 1986;35:797-801.

11. Segato T, Midena E, Grigoletto F, Zucchetto M, Fedele D, Piermarocchi S, et al. The Epidemiology and Prevalence of Diabetic Retinopathy in the Veneto Region of North East Italy. Diabetic Med. 1991;8(S2):S11-6. do1:10.1111/.1464-5491.1991.tb02149.x.

12. Cahill M, Halley A, Codd M, O'Meara N, Firth R, Mooney D, et al. Prevalence of diabetic retinopathy in patients with diabetes mellitus diagnosed after the age of 70 years. Br J Ophthalmol. 1997;81(3):21822. do1:10.1136/bjo.81.3.218.

13. Rema M, Premkumar S, Anitha B, Deepa R, Pradeepa R, Mohan V. Prevalence of Diabetic Retinopathy in Urban India: The Chennai Urban Rural Epidemiology Study (CURES) Eye Study. Investig Ophthalmol Vis Sci. 2005;46:2328-33.

14. Klein R, Klein BE, Moss SE, Davis ME, Demets DL. The Wisconsin epidemiologic study of diabetic retinopathy. III. Prevalence and risk of diabetic retinopathy when age at diagnosis is 30 or more years. Arch Ophtalmol. 1984;102:4527-32.

15. Shaikh R. Prevalence of dry eye disease in type 2 diabetic patients and its co-relation with the duration, glycemic control and retinopathy. Al Ameen J Med Sci. 2015;8:225-9.

16. Najafi L, Malek M, Valojerdi AE, Aghili R, Khamseh ME, Fallah AE. Dry eye and its correlation to diabetes microvascular complications in people with type 2 diabetes mellitus. J Diabetes Complications. 2013;27(5):459-62. doi:10.1016/j.jdiacomp.2013.04.006.

\section{Author biography}

O Revana Reddy, Post Graduate

B Asritha, Assistant Professor

K Sushma, Post Graduate

Cite this article: Reddy OR, Asritha B, Sushma K. Study of dry eye in diabetes mellitus type II and it's association with diabetic retinopathy. Indian J Clin Exp Ophthalmol 2020;6(4):626-628. 